cases of self-poisoning coming to hospital and not just with those cases somehow selected for psychiatric investigation.

Those with no psychiatric illness tended to be younger; those with organic illnesses were generally old. Apart from this the relation between diagnosis and age was not close.

The principal diagnosis was related to the index of endangering life (Table VIII). The acts of patients with a formal psychiatric illness (excluding character disorder) were more life-endangering than those of patients with personality abnormality or those of patients without a psychiatric illness. Yet the majority of acts of even the more seriously ill people were clearly pointed towards survival.

\begin{tabular}{|c|c|c|c|c|c|}
\hline \multicolumn{3}{|c|}{ Predictable Outcome } & \multirow{2}{*}{$\begin{array}{c}\begin{array}{c}\text { All } \\
\text { Psychiatric } \\
\text { Illnesses } \\
(292)\end{array} \\
25 \% \\
11 \% \\
20 \% \\
43 \%\end{array}$} & \multirow{2}{*}{$\begin{array}{c}\begin{array}{c}\text { Personality } \\
\text { Disorder } \\
\text { Only } \\
(108)\end{array} \\
12 \% \\
11 \% \\
26 \% \\
51 \%\end{array}$} & \multirow{2}{*}{$\begin{array}{c}\begin{array}{c}\text { No } \\
\text { Psychiatric } \\
\text { Diagnosis } \\
(113)\end{array} \\
12 \% \\
10 \% \\
30 \% \\
49 \%\end{array}$} \\
\hline $\begin{array}{l}\text { Death . . . } \\
\text { Death probable . } \\
\text { Death unlikely . } \\
\text { Certain to survive }\end{array}$ & $\begin{array}{l}\cdots \\
\cdots \\
\cdots\end{array}$ & $\begin{array}{l}\cdots \\
\cdots \\
\cdots\end{array}$ & & & \\
\hline
\end{tabular}
combined.

The different diagnostic groups do not vary much in the methods they choose. The only features of note are that those without a psychiatric illness use aspirin rather more often than the others, and that people with an organic illness use coal-gas more. These findings are probably attributable to the ages of those involved.

Quite commonly patients who were suffering from depression had an underlying character disorder. The combination of depression and psychopathy often occurred. This conjunction seems especially prone to manifest in self-poisoning acts. Personality disorder, either as a principal or as an accessory diagnosis, was recognized in $41 \%$ of men and $27 \%$ of women patients, and about half of these were classed as psychopaths. A smaller proportion appeared to us to be abnormally immature in their outlook. No other sort of personality abnormality occurred frequently.

Associated diagnostic factors included alcoholism, drug addiction, epilepsy, and subnormality. Fifty-two per cent. of men had one or more of these conditions, and the dominant factor was alcoholism. Thirty-nine per cent. of the men and $8 \%$ of the women were alcoholics, seasoned drinkers, unquestionably addicted, many of them bearing the physical signs of chronic alcoholism. Alcoholism is a major factor predisposing to selfpoisoning. So is alcohol itself : $56 \%$ of the men and $23 \%$ of the women had been drinking just before the act took place- a deliberate act in every case. The methods adopted by alcoholics did not differ from those employed by the generality of patients, and the acts which led to their admission, and to the admission of those inebriated at the time, were neither more nor less serious than those of other people. But of the six patients, four men and two women, who killed themselves within a year of discharge, five were alcoholics.

\section{Recommended Disposal}

Twenty-six per cent. of the patients were sent for furtner in-patient psychiatric treatment, $38 \%$ were recommended outpatient treatment, which, unless they had previously been under the care of another Edinburgh psychiatrist, was carried out by our own service. For $36 \%$ no further psychiatric treatment was arranged (Table IX): sometimes because the patient refused our suggestion, but in most cases because we did not think that further treatment was called for. This was either because there was no condition present to treat, and the tangled precipitating social web had been unravelled while the patient was still in our care, or because the personality disorder from which the patient suffered was so ingrained that treatment would not avail. Diagnosis is correlated with disposal, but this was not primarily decided on the basis of the diagnosis made. The proportion recommended for in-patient care must inevitably depend upon availability of psychiatric beds. Similarly the extent of outpatient care depends upon the amount of psychiatric time allotted for this.

\begin{tabular}{c|c|c|c|c}
\multicolumn{6}{c}{ TABLE IX.-Diagnosis and Disposal } \\
\hline & $\begin{array}{c}\text { Patients with } \\
\text { a Psychiatric } \\
\text { Illness } \\
(286)\end{array}$ & $\begin{array}{c}\text { Patients with } \\
\text { Personality } \\
\text { Disorder } \\
\text { Only (103) }\end{array}$ & $\begin{array}{c}\text { Patients with } \\
\text { no Psychiatric } \\
\text { Diagnosis } \\
(112)\end{array}$ & $\begin{array}{c}\text { All } \\
\text { Patients* } \\
(501)\end{array}$ \\
\hline $\begin{array}{c}\text { Further } \\
\text { psychiatric } \\
\text { treatment } \\
\begin{array}{c}\text { No further } \\
\text { treatment }\end{array}\end{array}$ \\
$\begin{array}{c}\text { In-patient } \\
\text { Out-patient }\end{array}$ & $\begin{array}{c}37 \% \\
40 \%\end{array}$ \\
\hline
\end{tabular}

* Excluding 21 patients who discharged themselves before disposal was arranged.

It does not follow that the patient can benefit from treatment only if he has a psychiatric illness. Nearly half of those without such illness were judged to be helpable by further care, a term which embraces social work as well as psychiatric therapy. Generally this was on an out-patient basis, but $8 \%$ of them required to be in-patients so that they might properly be tided over the acute crisis situation which had caused their act.

[Part II will appear in our next issue.]

\title{
Pulmonary Function in Acute Myocardial Infarction
}

\author{
M. W. MCNICOL, M.B., M.h.C.P. ; BRIAN J. KIRBY,* M.B.; K. D. BHOOLA,* M.B., B.CH., B.A.O., PH.D.; \\ M. E. EVEREST,* M.B., M.R.C.P. ; H. V. PRICE,* M.B., D.C.H. ; S. F. FREEDMAN,* M.B., M.R.C.P.
}

Brit. med. F., 1965, 2, 1270-1273

In studying the disturbance of arterial blood gases in patients with acute myocardial infarction it soon became apparent that many had evidence of pulmonary congestion ( $\mathrm{McNicol}$ et al., 1964). This paper reports the changes in arterial blood gases found in a large number of patients with acute myocardial infarction and the results of several procedures carried out with

* Cardtothoracic Department, Central Middlesex Hospital, London. a view to assessing the effect of pulmonary congestion on the function of the lungs.

\section{Material}

Observations were nade in the years 1962-4 on patients admitted to Central Middlesex Hospital with acute myocardial infarction and pulmonary congestion from other causes; those 
with chronic bronchitis or pulmonary embolism were excluded. The patients' ages ranged from 38 to 83 years, and they were classified into the following groups:

Group 1: Uncomplicated myocardial infarction (14 patients).

Group 2: Myocardial infarction with "shock" (2 patients).

Group 3: Myocardial infarction with "shock" and pulmonary congestion (13 patients).

Group 4: Myocardial infarction with pulmonary congestion (44 patients).

Group 5: Pulmonary congestion from other causes (19 patients). gradient. When no expired air collection was made alveolararterial oxygen tension gradient was calculated, an R.Q. of 0.8 being assumed.

Oxygen $(100 \%)$ was given by means of a valve-box and reservoir bag. Blood samples were taken after 20 minutes.

In 11 patients blood was taken before and four hours after the intravenous administration of a diuretic (chlorothiazide $0.5 \mathrm{~g}$. or ethacrynic acid $100 \mathrm{mg}$.). In these patients the F.E.V..$_{1}$ and F.V.C. were also measured with a portable bellows spirometer (Vitalograph, Garthur).

\section{Diagnostic Criteria}

Myocardial infarction was diagnosed when there was an appropriate history accompanied by electrocardiographic evidence of recent transmural infarction (W.H.O., 1959) or by lesser electrocardiographic changes suggestive of myocardial infarction if these were accompanied by a rise in serum glutamic-oxaloacetic transaminase or serum hydroxybutyric dehydrogenase (Wilkinson, 1962), or by the finding of acute coronary occlusion or myocardial infarction at necropsy. Pulmonary congestion was diagnosed when examination of the chest showed basal or more widespread crepitations not cleared by cough, or rhonchi in the absence of a history of bronchitis, or a combination of these signs. Twenty-three of the 57 patients in groups 1 and 4 with these signs were acutely dyspnoeic and orthopnoeic; the remainder were not breathless.

"Shock" was diagnosed if there was persistent hypotension - systolic blood-pressure of less than $90 \mathrm{~mm}$. Hg for more than 30 minutes. Most of the patients in this group had hypotension for much longer and had other manifestations of circulatory failure-pallor, coldness of the skin, restlessness, etc.

\section{Methods}

Blood was taken by percutaneous puncture of the brachial or femoral arteries, a No. 1 hypodermic needle (21 S.W.G., $0.8 \mathrm{~mm}$. external diameter) being used. All patients were in bed, and, unless dyspnoeic, were lying supine. When more prolonged studies were made a Teflon catheter was inserted into the brachial artery.

All samples were analysed immediately. Oxygen saturation was measured with a Brinkman Haemoreflector (Kipp and Zonen, Delft). In some patients oxygen tension was measured directly with a polarographic electrode (Beckman macroelectrode, Beckman Instruments Inc.). In the remainder oxygen tension was calculated from the oxygen saturation by the use of Dill's dissociation curve, taking into account the effect of $p \mathrm{H}$. The overall accuracy of this procedure is $\pm 5 \mathrm{~mm}$. $\mathrm{Hg}$ at oxygen saturations below $90 \%$ and $\pm 10 \mathrm{~mm}$. above $90 \%$.

Carbon dioxide tension was measured by a Severinghaus $\mathrm{CO}_{2}$ electrode (Severinghaus and Bradley, 1958) and $\mathrm{pH}$ with an Astrup micro-electrode (Radiometer, Copenhagen). Plasma bicarbonate was calculated from the observed values by use of the Henderson-Hasselbach equation.

Expired-air collections were made, a low-resistance valve (Siebe Gorman) and a lightweight Douglas bag being used. Collections were taken over two minutes after an initial period of acclimatization to the mouthpiece. Gas volume was measured with a dry-gas meter (Parkinson-Cowan). The expired air was analysed for oxygen and carbon dioxide by means of Lloyd's modification of the Haldane apparatus (Lloyd, 1958). From these figures and the values of simultaneously taken arterial blood the following were calculated: respiratory exchange ratio; dead-space/tidal-volume ratio and physiological dead space ; alveolar oxygen tension ; alveolar-arterial oxygen tension

\section{Results}

Oxygen (Table I).-Oxygen saturation was normal only in group 1 (uncomplicated myocardial infarction), but even in this group the mean oxygen tension was below normal and the alveolar-arterial oxygen tension gradient increased. "Shock" (group 2) and pulmonary congestion (group 4) were associated with greater changes and arterial desaturation. The most severe changes were found in patients with both "shock" and pulmonary congestion (group 3). Pulmonary congestion not due to acute myocardial infarction (group 5) produced changes similar to those seen in groups 2 and 4.

TABLE I.-Arterial Blood: Oxygen

\begin{tabular}{c|c|c|c|c|c}
\hline Group & Diagnosis & $\begin{array}{c}\text { No. of } \\
\text { Cases }\end{array}$ & $\begin{array}{c}\text { Mean } \mathrm{O}_{2} \\
\text { Satn. } \\
(\%)\end{array}$ & $\begin{array}{c}\text { Mean } \\
\text { PaO } \\
(\mathrm{mm.Hg})\end{array}$ & $\begin{array}{c}\text { A-a } \\
\text { Gradient } \\
(\text { mm.Hg) }\end{array}$ \\
\hline 1 & $\begin{array}{c}\text { Myocardial infarction } \\
\text { Myocardial infarction with } \\
\text { shock } \\
\text { Myocardial infarction with } \\
\text { shock and pulmonary } \\
\text { congestion }\end{array}$ & 14 & $93 \pm 3^{*}$ & $73 \pm 14^{*}$ & $31 \pm 16^{*}$ \\
3 & $\begin{array}{c}\text { Myocardial infarction and } \\
\text { pulmonary congestion }\end{array}$ & 44 & $82 \pm 8$ & $53 \pm 14$ & $58 \pm 14$ \\
5 & $\begin{array}{c}\text { Pulmonary congestion } \\
\text { from other causes }\end{array}$ & 19 & $86 \pm 8$ & $55 \pm 13$ & $54 \pm 15$ \\
\hline Normal values (Comroe et al., 1962) & Above 93 & $85-95$ & 10 \\
\hline
\end{tabular}

* The figures following the mean values represent one standard deviation.

Carbon Dioxide Tensions, $p H$, and Plasma Bicarbonate (Table II).-Group mean values for carbon dioxide tension were at the lower limit or slightly below normal. Group mean values for $\mathrm{pH}$ and bicarbonate were normal. Individual patients with "shock" showed a fall in $p \mathrm{H}$ and bicarbonate.

TABLE II.-Arterial Blood: Carbon Dioxide, $p H$, and Bicarbonate

\begin{tabular}{|c|c|c|c|}
\hline Group & $\underset{p \mathrm{H}}{\text { Mean }}$ & $\begin{array}{c}\text { Mean } \\
\text { Pco }_{2} \\
(\mathrm{~mm} . \mathrm{Hg})\end{array}$ & $\begin{array}{c}\text { Mean Plasma } \\
\text { Bicarbonate } \\
(\mathrm{mEq} / \mathrm{l} .)\end{array}$ \\
\hline $\begin{array}{l}1 \\
2 \\
3 \\
4 \\
5\end{array}$ & $\begin{array}{c}7 \cdot 41(7 \cdot 35-7 \cdot 48) * \\
7 \cdot 41 \\
7 \cdot 32(7 \cdot 17-7 \cdot 55) \\
7 \cdot 39(7 \cdot 32-7 \cdot 48) \\
7 \cdot 43(7 \cdot 37-7 \cdot 49)\end{array}$ & $\begin{array}{c}37 \pm 5 t \\
26 \\
32 \pm 8 \\
37 \pm 5 \\
33 \pm 6 \\
\end{array}$ & $\begin{array}{l}23 \pm 3 t \\
16 \\
21 \pm 7 \\
22 \pm 4 \\
21 \pm 3\end{array}$ \\
\hline $\begin{array}{l}\text { Normal values } \\
\text { (Comroe et al., } \\
\text { 1962) .. }\end{array}$ & $7 \cdot 36-7 \cdot 45$ & $36-4 j$ & $20-24$ \\
\hline
\end{tabular}

* One standard deviation range.
t One standard deviation.

\section{Expired-air Collections (Table III)} patients in whom it was measured and the physiological dead space was raised in the majority, sometimes strikingly so (Cases 5 and 88). In only two patients was the value of the respiratory exchange ratio above 1 , indicating that most of the gas collections were satisfactory.

\section{Arterial Blood Gas Analysis}

The dead-space/tidal-volume ratio was raised in all the 


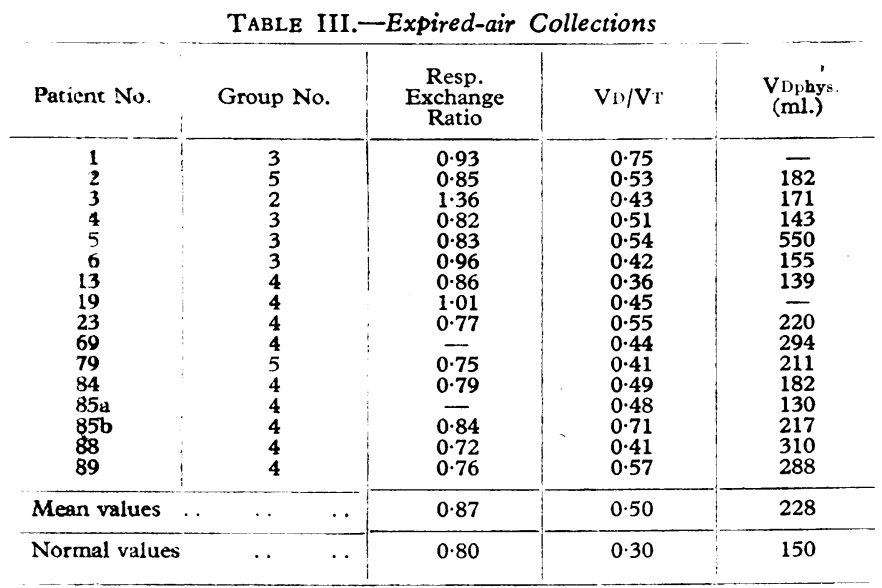

\section{Effects of Oxygen (Table IV and Fig. 1)}

Administration of $100 \%$ oxygen by means of a mouthpiece and valve-box resulted in a rise in the oxygen tension in all the patients studied. In seven patients a normal rise in oxygen tension was not obtained. This was especially striking in two patients. The reasons for this are discussed below. The diagnostic categories of these patients are shown in the Table.
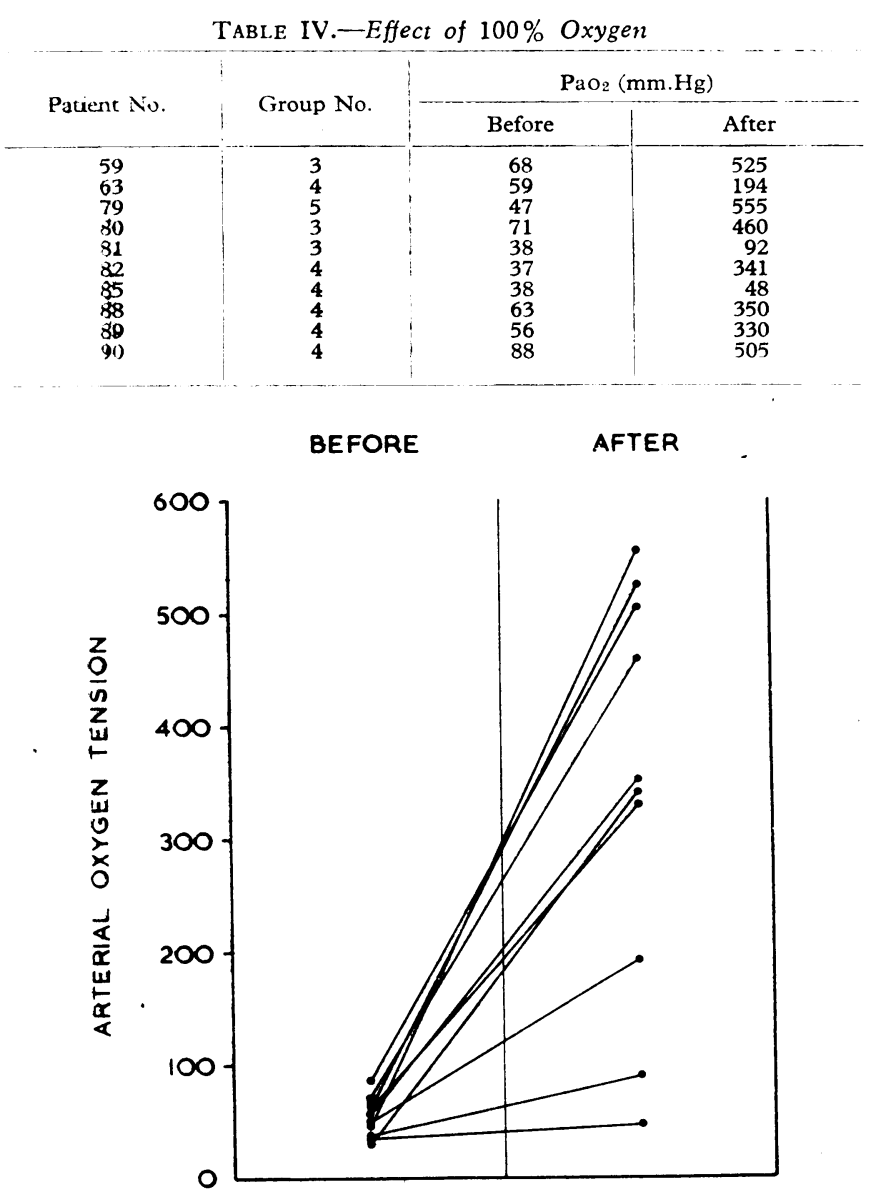

FIG. 1.-Effects on arterial oxygen tension of the administration of $100 \%$ oxygen.

Effects of Diuresis (Tables V and VI, Fig. 2)

When the initial oxygen saturation was less than $90 \%$ a significant rise in the arterial oxygen tension was produced by diuretics $(P<0.01)$, together with a fall in alveolar-arterial gradient. The F.E.V., and F.V.C. also rose in these patients.
TABLE V.-Effect of Diuretics. Arterial Oxygen

\begin{tabular}{|c|c|c|c|c|c|c|}
\hline \multirow[b]{2}{*}{$\begin{array}{l}\text { Patient } \\
\text { No. }\end{array}$} & \multicolumn{3}{|c|}{ Before } & \multicolumn{3}{|c|}{ After } \\
\hline & $\underset{(\%)}{\mathrm{O}_{2} \text { Satn. }}$ & $\underset{(\mathrm{mm} . \mathrm{Hg})}{\mathrm{PaO}_{2}}$ & 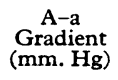 & $\underset{(\%)}{\mathrm{O}_{2} \text { Satn. }}$ & $\underset{(\mathrm{mm} . \mathrm{Hg})}{\mathrm{PaO}_{2}}$ & $\begin{array}{c}\text { A-a } \\
\text { Gradien } \\
\text { (mm. Hg }\end{array}$ \\
\hline \multicolumn{7}{|c|}{ Saturation less than $90 \%$} \\
\hline $\begin{array}{l}57 \\
60 \\
69 \\
73 \\
82 \\
84 \\
85 \\
89\end{array}$ & $\begin{array}{l}86 \\
89 \\
89 \\
89 \\
85 \\
86 \\
71 \\
77\end{array}$ & $\begin{array}{l}53 \\
54 \\
55 \\
59 \\
61 \\
51 \\
37 \\
41\end{array}$ & $\begin{array}{l}53 \\
57 \\
56 \\
54 \\
35 \\
55 \\
77 \\
67\end{array}$ & $\begin{array}{l}95 \\
90 \\
93 \\
94 \\
94 \\
91 \\
66 \\
81\end{array}$ & $\begin{array}{l}77 \\
58 \\
63 \\
73 \\
75 \\
58 \\
36 \\
45\end{array}$ & $\begin{array}{l}38 \\
54 \\
45 \\
39 \\
34 \\
52 \\
66 \\
51\end{array}$ \\
\hline \multicolumn{7}{|c|}{ Saturation over $90 \%$} \\
\hline $\begin{array}{l}61 \\
63 \\
87\end{array}$ & $\begin{array}{l}96 \\
92 \\
90\end{array}$ & $\begin{array}{l}87 \\
63 \\
61\end{array}$ & $\begin{array}{l}22 \\
38 \\
42\end{array}$ & $\begin{array}{l}97 \\
91 \\
92\end{array}$ & $\begin{array}{l}93 \\
61 \\
65\end{array}$ & $\begin{array}{l}15 \\
45 \\
43\end{array}$ \\
\hline
\end{tabular}

TABLe VI.-Effect of Diuretics. F.E.V. and F.V.C.

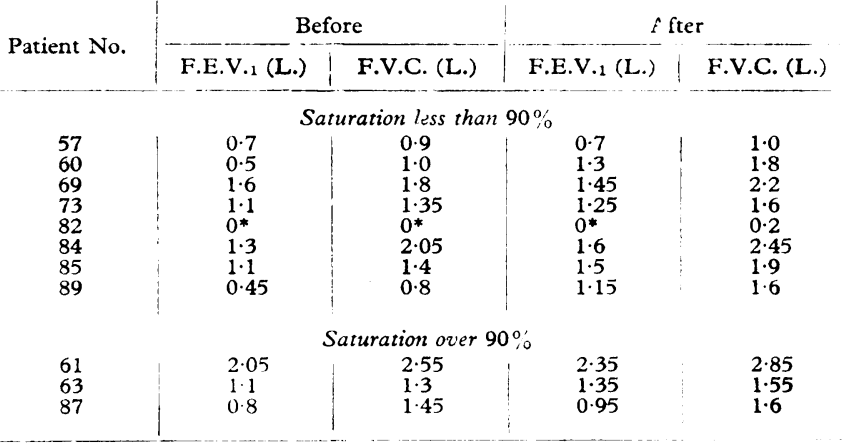

*. Unrecordable.

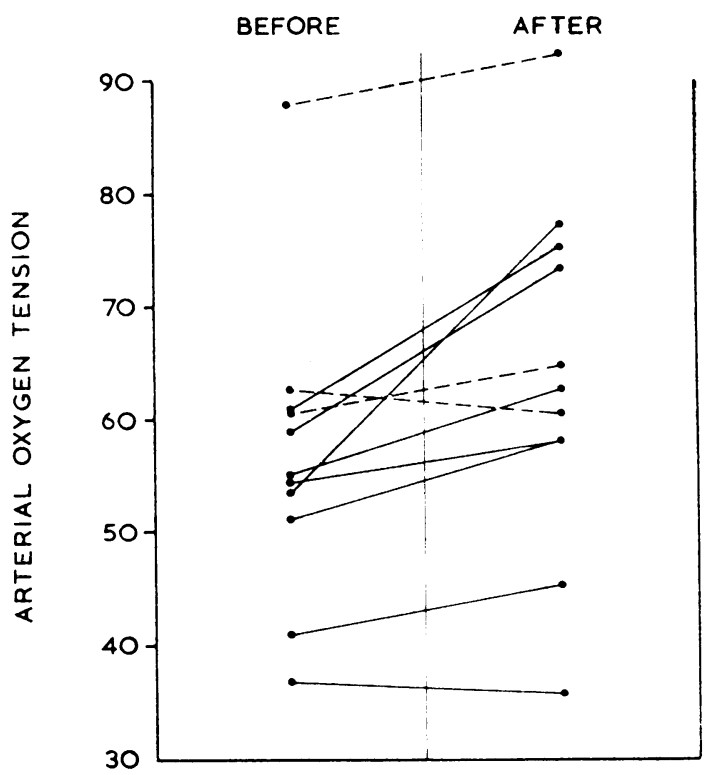

Fig. 2.-Effect on arterial oxygen tension of the administration of an intravenous diuretic. The continuous lines denote patients in an intravenous diuretic. The continuous lines denote patiats in whom the oxygen saturation was below $90 \%$ at the start; the diuresis.

\section{Discussion}

Of the 73 patients with acute myocardial infarction $57(78 \%)$ had evidence of pulmonary congestion as defined by strict clinical criteria. Other complications, notably "shock," were much less common-15 cases ( $21 \%$ ). That pulmonary congestion is a very common complication of myocardial infarction is not surprising. Lee (1957) has recorded an almost invariable rise in central venous pressure in acute myocardial infarction; a rise in pulmonary venous pressure must be even more common, for the left ventricle is predominantly involved in 
myocardial infarction. It might be suggested that our diagnostic criteria for pulmonary congestion were so wide as to be of little significance, but the results of blood-gas analysis on our patients show clearly that even these minor clinical signs were associated with a well-marked deterioration of pulmonary function. Like previous observers (Vitale et al., 1954), we have found no correlation between the clinical assessment of severity of pulmonary congestion and the functional changes it produces. A few basal crepitations may be associated with as great a functional disturbance as many crepitations in both lung fields. Our findings show that not only is pulmonary congestion a common complication of myocardial infarction, but also that it produces significant impairment of oxygenation by the lung.

The characteristic change in the arterial blood gases in myocardial infarction is a fall in arterial oxygen tension with an increase in the alveolar-arterial gradient. The fall in oxygen tension is not due to underventilation of the lungs; in most of the patients the low carbon dioxide tension indicates overventilation. These changes were not pronounced in those patients with uncomplicated myocardial infarction, but were most often found in those with pulmonary congestion. Similar changes were found in those with "shock," but "shock" was almost invariably accompanied by pulmonary congestion.

Our investigations are not sufficient to give precise information on the mechanism of this disorder of pulmonary function. Either pulmonary congestion with a rise in pulmonary venous pressure or a fall in cardiac output consequent on myocardial infarction (Malmcrona and Varnauskas, 1964) could cause disturbance of ventilation-blood-flow relationships in the lungs. Pulmonary congestion with interstitial oedema would impair gas transfer from the alveolus to pulmonary capillary. Either of these mechanisms would be associated with a rise in alveolararterial oxygen gradient. The increase in alveolar-arterial oxygen gradient in the two patients with myocardial infarction and persistent hypotension suggests that ventilation-blood-flow disturbance secondary to change in cardiac output can be important; this would be expected in an organ like the lung, whose perfusion is largely determined by gravity (West, 1963), and the pattern of perfusion of which will be very sensitive to changes in cardiac output. The gas collections showed a large physiological dead space, indicating ventilation of unperfused alveoli in keeping with such a hypothesis. Breathing of pure oxygen should abolish the hypoxaemia produced in either of these ways, and 7 of the 10 patients to whom pure oxygen was given showed such a response. In the remaining three there was a much smaller rise in oxygen tension. It seems unlikely that an anatomic shunt is present in these cases. It is suggested that the failure to achieve a satisfactory rise in oxygen tension is due to a very severe ventilation-blood-flow imbalance with perfusion of completely unventilated alveoli, the circulatory counterpart of the increased dead space.

Unlike the changes associated with "shock" in myocardial infarction which are resistant to treatment (MacKenzie et al., 1964), we found it was possible to influence the changes associated with pulmonary congestion not only by oxygen therapy but also by the use of diuretics. A significant improvement was produced within four hours, not only in arterial blood gases but also in ventilatory function, by the use of a rapidly acting intravenous diuretic in those patients in whom there was a marked physiological disturbance $\left(\mathrm{O}_{2}\right.$ saturation less than $90 \%)$. Patients with less abnormality of blood gases did not show any significant response. Thus the most common hypoxaemia in acute myocardial infarction can be relieved by treatment- "symptomatically" by oxygen therapy and more fundamentally by diuretics-and the more severe the hypoxaemia the more likely it is to be relieved.
There was no difference in the severity of the blood-gas changes in those with pulmonary congestion from acute myocardial infarction and those with pulmonary congestion from other causes. Within the scope of our investigation there were no distinguishing features in the physiological changes produced by either cause.

The abnormalities we have described and their response to treatment may be of considerable significance. The patients who died had significantly greater arterial hypoxaemia than those who survived (mean oxygen tension of those who died, $52 \mathrm{~mm}$. and $\mathrm{O}_{2}$ saturation $83 \%$, compared with mean $\mathrm{O}_{2}$ tension of $63 \mathrm{~mm}$. and $\mathrm{O}_{2}$ saturation of $89 \%$ in survivors$\mathbf{P}<0.01$ ). Of the 23 patients with oxygen saturation below $85 \% 13(56 \%)$ died, and of the 64 with oxygen saturation above $85 \% 12(19 \%)$ died. The more severe hypoxaemia may only reflect greater severity of the disease process, but it may also be a contributory factor in the fatal outcome, as was found by Freeman and Nunn (1963) in experimentally induced shock, when anoxia caused respiratory depression, not respiratory stimulation. In acute myocardial infarction oxygen therapy will rapidly relieve the hypoxaemia most commonly foundthat due to pulmonary congestion-and diuretic therapy will bring about more fundamental improvement.

Follow-up studies on these patients are not yet complete; they will be published at a later date. The abnormalities of arterial oxygenation present in the acute stage have greatly diminished or disappeared in 37 of the patients so far studied. Disappearance of the chest signs has occurred in 30 of these cases.

\section{Summary}

Of 73 patients with acute myocardial infarction 57 (78\%) showed evidence of pulmonary congestion. This was associated with arterial hypoxaemia, which could be relieved by oxygen therapy or, if severe, by diuretics. It is suggested that pulmonary congestion is the commonest cause of hypoxaemia in myocardial infarction and that its treatment may improve the prognosis in acute myocardial infarction.

Our thanks are due to Dr. E. J. M. Campbell, who first suggested this investigation, for his continued advice and helpful criticism. We are also grateful to the physicians at the Central Middlesex Hospital (Dr. R. Asher, Dr. K. P. Ball, Dr. H. Joules, and Dr. F. Avery Jones), on whose patients these observations were made. The majority of the blood-gas estimations were carried out by Miss C. Bruyns and Miss M. O'Brien, whose help it is a pleasure to acknowledge. Dr. M. W. McNicol, Miss Bruyns, and Miss O'Brien were supported by a grant from the Medical Research Council, who also financed the running of the laboratory.

\section{REFERENCES}

Comroe, J. H., Forster, R. E., Dubois, A., Briscoe, W. A., and Carlsen, E. (1962). The Lung, p. 323 et seq. "Year Book Medical Publishers, Chicago.

Freeman, J., and Nunn, J. F. (1963). Clin. Sci., 24, 135.

Lee, G. de'J. (1957). Brit. Heart f., 19, 117.

Lloyd, B. B. (1958). \%. Physiol. (Lond.), 143, 5 P. Staunton, H. ', Taylor, S. H., Flenley, D. C., McDonald, A. H., McNicol, M. W., Kirby, B. J., Everest, M. S., Freedman, S., and Bhoola, K. D. (1964). Ibid., 2, 1180.

Malmcrona, R., and Varnauskas, E. (1964). Acta med. scand., 175, 1. Severinghaus, J. W., and Bradley, A. F. (1958). f. appl. Physiol., 13, Vitale, 515.

Vitale, A., Dumke, P. R., and Comroe, J. H. (1954). Circulation, 10, 81. West, J. B. (1963). Lancet, 2, 1055.

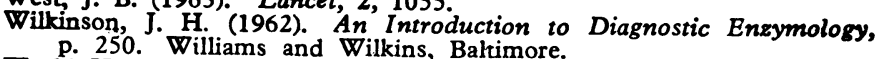
p. 250. Williams and Wilkins, Baltimore.
World Health Organization (1959). Techn. Rep. Ser., No. 168. 